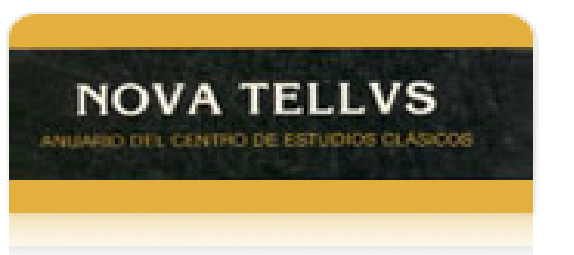

Nova Tellus

ISSN: 0185-3058

novatelu@servidor.unam.mx

Centro de Estudios Clásicos México

López Cruz, Paula

La seditio Manliana: un exemplum ficticio (Liv., VI, 11 y 14-20)

Nova Tellus, vol. 32, núm. 1, 2014, pp. 121-135

Centro de Estudios Clásicos

Distrito Federal, México

Disponible en: http://www.redalyc.org/articulo.oa?id=59137776005

- Cómo citar el artículo

- Número completo

- Más información del artículo

- Página de la revista en redalyc.org

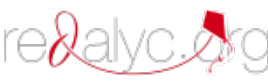

Sistema de Información Científica

Red de Revistas Científicas de América Latina, el Caribe, España y Portugal

Proyecto académico sin fines de lucro, desarrollado bajo la iniciativa de acceso abierto 


\title{
La seditio Manliana: un exemplum ficticio (Liv., VI, 11 y 14-20)
}

The Seditio Manliana: a Fictional Exemplum (Liv., VI, 11 and 14-20)

\author{
Paula LÓPEZ CRUZ \\ Instituto de Investigaciones Filológicas, UNAM \\ paula@unam.mx
}

\begin{abstract}
Resumen: En este artículo se examina la forma en que Livio emplea el tópico de la locura para recrear la historia del patricio Marco Manlio Capitolino como exemplum del hombre que aspiró al reino de Roma y por cuya ambición fue sentenciado a ser despeñado de la roca Tarpeya como justo castigo. Estrategia retórica que se empleó en la República tardía para desprestigiar a los adversarios políticos.
\end{abstract}

ABSTRACT: This article describes how Livy uses the topic of madness to recreate patrician M. Manlius Capitolinus's history as exemplum of a man who aspired to the kingdom of Rome and whose ambition led him to be sentenced to headlong hurling from the Tarpeian Rock. Such punishment was a rhetorical strategy in the late Republic used to discredit political opponents.

Palabras Clave: seditio Manliana, tópico de la locura, Livio.

KEY WORDS: seditio Manliana, topic of madness, Livy.

RECIBIDO: 23 de abril de 2014 - ACEPTADO: 31 de julio de 2014.

El relato del historiador Tito Livio en torno a la sedición ${ }^{1}$ de Marco Manlio Capitolino ha sido objeto de diversos análisis por parte de reconocidos estudiosos. De estas revisiones ha quedado claro que la versión del autor latino está llena de sucesos anacrónicos, dobletes, transferencias de la historia de Grecia e inconsistencias; en pocas palabras, carece de exactitud histórica, aunque no se niega la historicidad del personaje ni del acontecimiento. Por lo demás, es sabido que el interés de Livio por dejar ejemplos de conductas lo llevó a reelaborar esa historia ya conocida en su tiempo, manejando los datos que sus fuentes le proporcionaban para transmitir su propia interpretación del pasado. Así lo plantea en el prefacio general a su Historia de Roma:

${ }^{1}$ Desde la perspectiva de los optimates, una seditio era más o menos equivalente a "revolución", en el sentido de que se promovían cambios importantes en la estructura política o socio-económica. Sistemáticamente, estos cambios fueron considerados como una amenaza para la "libertas de los optimates, que se basa en el respeto de su posición de preeminencia, justificada por el mos maiorum”, según Marco-Pina 2000, p. 268. 
Lo saludable y fructífero con respecto al conocimiento de los hechos es, sobre todo, que tú pienses en las enseñanzas de todo ejemplo puestas en un testimonio ilustre; que concibas, de un lado, cuál ejemplo imitar para tu bien y para el de tu república; de otro, cuál evitar como repugnante en su comienzo como repugnante en su final. ${ }^{2}$

El episodio histórico de Manlio conocido como la seditio Manliana es uno de los exempla que caracteriza al hombre codicioso de poder, cuyo fin es la muerte como justo castigo por su ambición. En este trabajo nos interesa poner de manifiesto que, en la confección del exemplum de Manlio como aspirante al reino de Roma, Livio usó la misma estrategia retórica que en la República tardía se empleó para desprestigiar a los adversarios políticos. ${ }^{3}$ El interés que puede haber para una sociedad como la nuestra en hacer un análisis sobre este personaje estriba en entender cómo puede construirse una imagen equivocada y negativa de un hombre indeseable para los poderosos por sus actos en beneficio de las personas más desprotegidas; cómo es que los actos y palabras de un hombre pueden ser manipulados hasta lograr que sea considerado peligroso para la sociedad. Una manera eficaz de anular movimientos de transformación social.

Antes de pasar al análisis, dedicamos unas líneas a los pocos datos que Livio proporciona de Manlio. Su primera aparición tiene lugar en el libro V, cuando es nombrado cónsul junto con L. Valerio Potito en el año 392. En este pasaje, el autor comenta que a Manlio "después se le dio el nombre de Capitolino". ${ }_{4}^{4}$ Durante su consulado se celebran los juegos magnos y la consagración del templo de Juno Reina, que M. Furio Camilo había prometido en la guerra de Veyes. Por los resultados de la guerra con los ecuos en el Álgido, a Valerio se le concede la ceremonia del triunfo y a Manlio la de la ovación..$^{5}$ Después ambos cónsules renuncian por enfermedad.

2 Praef., 10: Hoc illud est praecipue in cognitione rerum salubre ac frugiferum, omnis te exempli documenta in inlustri posita monumento intueri; inde tibi tuaeque rei publicae quod imitere capias, inde foedum inceptu foedum exitu quod vites.

${ }^{3}$ Hinojo 1997-1998, pp. 199-205.

${ }^{4}$ Liv., V, 31, 1-8: M. Manlius, cui postea Capitolino fuit cognomen. Es una alusión al apodo que se ganó gracias a su hazaña en el Capitolio durante la invasión de los galos (cf. Liv., VI, 17, 5).

${ }^{5}$ Dependiendo de la cantidad de muertos causados al enemigo, el senado concedía los honores del triunfo o de la ovación al general victorioso. El día de la celebración del triunfo, el cortejo salía del Campo Marte y se dirigía al templo de Júpiter, en el Capitolio. El triunfador, vestido con la túnica palmata y la toga de púrpura, subía hasta el 
Más tarde, durante el asedio de los galos al Capitolio en el 390, Manlio juega un papel destacado al impedir el arribo de los galos que por un sendero se habían aproximado a la cima sureste del Capitolio donde se encontraba la ciudadela $(a r x)$. Su hazaña le mereció el reconocimiento de los demás soldados: le llevaron media libra de trigo y un cuarto de vino a su casa, situada en la ciudadela. Livio apunta que no era menor ese reconocimiento en medio de tanta escasez, puesto que todos estaban quitándose de la boca ese alimento para dárselo a Manlio. ${ }^{6}$ Sobre su personalidad dice que era un hombre distinguido en la guerra (uir bello egregius). ${ }^{7}$

En el 388 es nombrado interrey ${ }^{8} \mathrm{y}$, tres años después, es el protagonista de una sedición. ${ }^{9}$ El relato de este suceso está situado en un momento de crisis económica, porque muchos ciudadanos, que se habían visto en la necesidad de contraer deudas para reconstruir sus casas dañadas durante la invasión de los galos, no podían pagarlas. ${ }^{10}$ En dos ocasiones, el autor señala la difícil situación que estaba afrontando la mayor parte de la población, incluso los ricos, porque, al no pagar la deuda en el plazo acordado con el prestamista, la ley permitía someter a servidumbre al deudor para que pagara mediante su trabajo. ${ }^{11}$ El núcleo de la historia narrada por Livio puede reducirse a que Manlio rescata de la servidumbre a muchos plebeyos pagando sus deudas. El senado, temeroso de que Manlio pudiera llegar al poder con el apoyo de sus seguidores, recurre a los tribunos de la plebe para acusarlo del delito de pretender el reino de Roma (crimen regni). ${ }^{12}$ Aunque con dificultad, se logra sentenciarlo a ser despeñado de la roca Tarpeya.

Capitolio en un carro tirado por caballos blancos. El cortejo estaba formado por los magistrados y los senadores, la banda de músicos del ejército, los animales blancos para el sacrificio, el botín, los cautivos, los lictores, la cuadriga del triunfador, los escuadrones de caballería y, al final, el ejército vencedor. Durante el trayecto, los soldados solían hacer bromas a su general. El triunfo se hacía constar en los Fasti Capitolini. En cambio, la ovación fue una forma menor de celebrar el triunfo de un general, que entraba a Roma a pie o a caballo, vistiendo la toga praetexta.

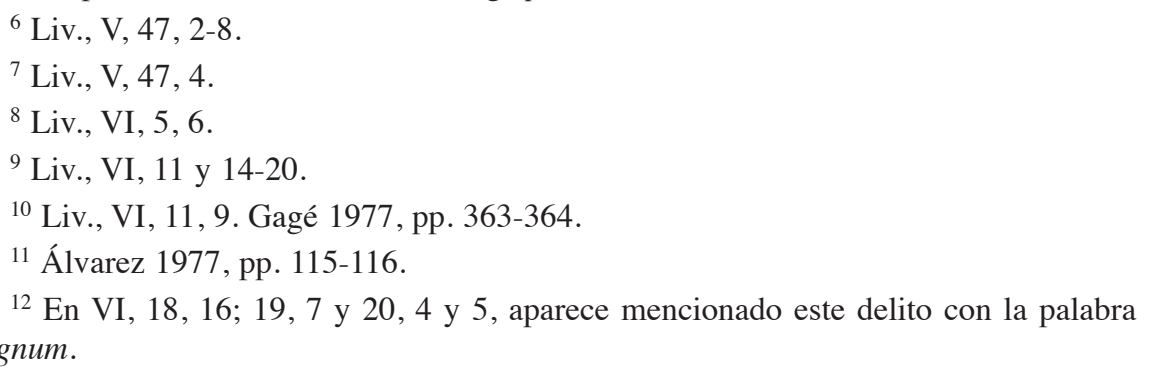


El interés de Livio en la narración del exemplum se centra en que esta historia sirva de testimonio para demostrar (probare) a los hombres, en palabras del autor, "cuáles honores y cuántos los ha vuelto no sólo desagradables sino también odiosos el deseo horrible de reinar". ${ }^{13}$ El exemplum cumplirá con su cometido en la medida en que sus destinatarios sepan interpretarlo como un modelo de conducta que debe ser rechazado. Para ello, Livio proporciona al lector algunas guías generales de la conducta negativa de Manlio para que sepa distinguirla e interpretarla como tal. Esas guías aparecen a lo largo de todo el relato a través de la voz del autor, quien, además de narrar la historia, aprovecha sus breves intervenciones para dar su punto de vista sobre los actos y palabras de Manlio, y de esta manera preparar al lector para el desenlace de la historia.

Para hacer verosímil la historia de Manlio, Livio tendrá como hilo conductor el tópico de la locura aplicado al ámbito social. La locura (insania, dementia) fue una enfermedad mental que afectaba al hombre y se manifestaba por una conducta perturbada e incomprensible. Este concepto fue ampliado y aplicado a otro tipo de insanus: el hombre que por su incapacidad de controlar los sentimientos negativos, como la ira, envidia o ambición, perdía la capacidad de reflexionar y de actuar en bien del interés público. ${ }^{14}$

El ideal de la sociedad romana "era mantener la unidad de todos los ciudadanos y defender los intereses de la comunidad". ${ }^{15}$ Para los antiguos romanos, la frase "los intereses de la comunidad" no significó lo mismo que ahora podríamos entender. Se trataba de conservar el orden establecido por los antepasados, de respetar el mos maiorum. ${ }^{16}$ Por ello, cualquier cambio que implicaba una alteración en la estructura política, social o económica se consideró una amenaza a la libertad, a la res publica. La clase gobernante, integrada por las familias más poderosas, equiparó los intereses de la república con los propios, por ello es válido decir que, en el ejercicio de las diferentes magistraturas, sus miembros velaban realmente por sus intereses.

En esta lógica, toda acción o propuesta favorable a la plebe, como un reparto de tierras, una condonación de deudas o venta de cereal a bajo costo,

${ }^{13}$ Liv., VI, 20, 5: quae et quanta decora foeda cupiditas regni non ingrata solum sed inuisa etiam reddiderit.

14 Muñiz 2000, pp. 237-241; López 2000, pp. 215-216.

${ }^{15}$ Hinojo 1997-1998, p. 197.

${ }^{16}$ Marco-Pina 2000, p. 268. 
se juzgó como una amenaza a la res publica por ser contraria a los intereses de la aristocracia. Así se entiende por qué se preocuparon por justificar el uso de la violencia contra los enemigos políticos que los afectaban.

Cuando las acciones de un hombre no coincidieron con los intereses del grupo dominante, aquél fue considerado un adversario político e incluso un hostis publicus. ${ }^{17}$ Entre los móviles tenidos en cuenta para difamarlo se cita el desequilibrio psicológico, o locura; ${ }^{18}$ pues sólo un desequilibrado perdía la capacidad de reflexionar correctamente y de aplicar sus virtudes personales en beneficio del interés común.

En la República tardía, se usaron sustantivos y adjetivos como amentia, amens, audacia, audax, furor, furens, temerarius, dedecus, scelus, insanus, para hacer el retrato de los rivales políticos como hombres degenerados, cuyas acciones podían considerarse perjudiciales para la ciudad. Personajes como los hermanos Graco, Catilina, Marco Antonio, Clodio, Verres, entre otros, fueron tildados de perversos sociales. ${ }^{19}$

Livio recoge las historias de Espurio Casio, ${ }^{20}$ Espurio Melio ${ }^{21}$ y Marco Manlio, tres hombres a quienes, por sus acciones favorables a la plebe, los gobernantes en turno los consideraron peligrosos, así que fueron acusados del mismo delito: aspirar al reino de Roma, y en consecuencia, como castigo por su proceder, pero sobre todo por su popularidad, fueron asesinados.

Las historias muestran similitudes en su desarrollo:

1. Son individuos destacados en la sociedad romana, por diversos motivos;

2. se ocupan de los principales problemas de la plebe en momentos de crisis

${ }^{17}$ Hinojo 1997-1998, p. 200.

${ }^{18}$ Id.

${ }^{19}$ López 2000, pp. 216-217; Hinojo 1997-1998, pp. 199-205.

${ }^{20}$ En el año 486, el cónsul Espurio Casio, después de pactar una alianza con los hérnicos, propuso que las dos terceras partes del territorio de ese pueblo, ya perteneciente a Roma, se repartieran entre los latinos y la plebe y que las tierras públicas de la ciudad, ocupadas por patricios, se repartieran también a los plebeyos. Según Livio, fue la primera ley agraria propuesta. Al concluir su mandato, fue acusado de pretender el reino de Roma, enjuiciado y condenado a muerte (Liv., II, 41).

${ }^{21}$ En el 440, Espurio Melio, un hombre particular, debido a la grave escasez de alimentos por la que atravesaba Roma, compró trigo y lo repartió entre la plebe; por esto, el encargado del abasto en Roma, Lucio Minucio, lo inculpó de aspirar al reino de Roma. Antes de ser enjuiciado, Espurio Melio fue asesinado por Cayo Servilio Ahala, jefe de la caballería. Al enterarse de su muerte, el dictador lo felicitó por haber salvado la República (Liv., IV, 12.6-14.6). 
social y económica; 3 . sus acciones les proporcionan gran popularidad entre la plebe, que los apoya; 4. cuando el patriciado los acusa, la plebe los abandona a su suerte; y 5 . mueren violentamente, sus bienes son confiscados y sus casas son derribadas. ${ }^{22}$

Estas afinidades evidencian que los tres episodios fueron modelados a partir de sucesos posteriores a su propia época. Pina sostiene que

habrían sido convertidos conscientemente en exempla de tiranicidios preventivos y utilizados de ese modo políticamente como medio de justificar el asesinato durante el período tardorrepublicano de políticos populares, de los que tanto sus iniciativas como su destino final eran fácilmente identificables con Casio, Melio y Manlio por la sencilla razón de que sus historias habían sido creadas de acuerdo con los acontecimientos contemporáneos. ${ }^{23}$

De acuerdo con esto, puede afirmarse que Livio no fue el primero ni el único que trató la historia de Manlio como el exemplum del hombre que perdió la vida por su ambición de poder; su contribución consistió en volverla más verosímil a partir de los sucesos conocidos. ${ }^{24}$ Él mismo tenía en mente que sus fuentes no proporcionaban datos específicos sobre el delito que se le imputó después, sino más bien hechos que por sí mismos tampoco conformaban el delito de pretender el reino de Roma: "cuando llegó el día, excepto sus reuniones con la multitud y sus palabras sediciosas y su liberalidad y su prueba engañosa, no encuentro en ningún autor cuáles fueron las imputaciones hechas al reo por sus acusadores, pertenecientes propiamente al delito de pretender el reino". ${ }^{25}$

Así pues, para hacer eficaz el exemplum, Livio decide modelar el retrato moral de Manlio como la de un hombre desequilibrado por su ambición, que va a ser esencial para comprender el desarrollo de los acontecimientos que narrará. Se trata de evocar una imagen adecuada para que el destinatario la relacione de inmediato con la imagen que políticos, como Cicerón, habían promovido de sus adversarios políticos. Poco a poco este retrato moral se verá confirmado a través de las accio-

22 Pina 2006, p. 9.

${ }^{23}$ Pina 2006, pp. 10-11.

${ }^{24}$ Livio tuvo a la mano diferentes versiones que no le proporcionaban detalles reales de la historia de Manlio, cf. Wiseman 1979, p. 46.

${ }^{25}$ Liv., VI, 20, 4: cum dies uenit, quae praeter coetus multitudinis seditiosasque uoces et largitionem et fallax indicium pertinentia proprie ad regni crimen ab accusatoribus obiecta sint reo, apud neminem auctorem inuenio. 
nes y palabras del personaje y a través de los comentarios del autor en diferentes lugares. Para lograr una mejor articulación del episodio, el autor alterna sus breves intervenciones como narrador y los discursos atribuidos a los diferentes personajes que participan.

Desde las primeras palabras con que empieza el relato: qui nimius ani$m i$ ("altanero"), ${ }^{26}$ Livio siembra, en sus destinatarios, la imagen de Manlio como un hombre afectado en su animo, desequilibrado, con características no propias de un patricio y de buena reputación (inclitae famae) como lo era Manlio. Ser altanero lo lleva a menospreciar a los otros hombres importantes de la ciudad (alios principes sperneret) y a envidiar únicamente a Camilo, por ser el único que sobresale en "honores y virtudes".

Con el primer discurso atribuido a Manlio, ${ }^{27} \mathrm{el}$ autor demuestra cómo es que la hazaña de haber impedido el arribo de los galos al Capitolio y a la ciudadela lo ha conducido a tener esos sentimientos de menosprecio y envidia. En el discurso, Manlio señala el reconocimiento de que ha sido objeto Camilo gracias a su actuación durante la invasión de los galos. En efecto, según la narración de Livio, después de este desastre, Camilo ha vuelto a desempeñar la magistratura de tribuno militar con poder consular y la de dictador. En cambio, Manlio no ha sido elegido para ninguna magistratura. Su reclamo es legítimo en el sentido de que ambos contribuyeron a vencer a los galos y sólo Camilo ha conseguido destacar políticamente. ${ }^{28}$ En su afán por demostrar que él también merece ese reconocimiento, minimiza la victoria de Camilo al decir que tomó por sorpresa a los galos cuando pesaban el oro del rescate; mientras que él se había enfrentado a hombres armados para salvaguardar el Capitolio. Desde la perspectiva de Manlio, parece estar justificado ese sentimiento de envidia a Camilo. Para cerrar esta parte, nuestro autor comenta que a este orgullo desmedido (his opinionibus inflato animo) se suma un defecto de su carácter: uehemens et impotens.

Con el término impotens se designaba al hombre que no tenía la capacidad de controlar sus sentimientos o pasiones. La falta de autocontrol llevaba a la desmesura, al desenfreno. ${ }^{29}$ Las acciones o palabras de estos desequilibrados resultaban insoportables para los demás. Por tanto, Livio, al calificar el carácter de Manlio con los adjetivos de vehemens

\footnotetext{
${ }^{26}$ Liv., VI, 11, 3.

${ }^{27}$ Liv., VI, 11, 4-11, 5.

28 Jaeger 1993, p. 354; Hellegouarch 1970, pp. 126-131.

${ }^{29}$ Luque 2009, pp. 63-65; Hinojo 1997-1998, pp. 203-204.
} 
e impotens, ${ }^{30}$ guía al lector hacia la manera en que debe interpretar las acciones que a continuación narrará de Manlio: su descontrol se manifiesta en sus palabras y acciones dirigidas a favorecer a la plebe, con tal de ganar el apoyo que necesita para obtener el poder que no ha logrado a través de los medios institucionales.

Un civis romanus debe mirar por el bien de la patria, de los dioses y de la comunidad; así como saber actuar desde la posición en la que le toca estar. Poco antes del episodio que nos ocupa, Livio ha proporcionado un ejemplo de la conducta que un buen ciudadano debe observar: el año anterior, ante la inminencia de la guerra contra los volscos, los tribunos militares deciden ponerse de acuerdo para que uno de ellos dirija la guerra y, por unanimidad, eligen a Camilo. El senado celebra que, gracias al reconocimiento de la superioridad de su colega, ya no habrá necesidad de nombrarlo dictador. ${ }^{31}$ Este ejemplo debió seguir Manlio y aceptar que Camilo continuamente estuviera en los cargos.

Una vez planteada la personalidad de Manlio como un hombre desequilibrado a causa de su codicia por el poder, Livio necesita demostrar la peligrosidad de sus palabras y acciones. Por ello, el desarrollo de los acontecimientos será expuesto como si se tratara de un plan.

Así pues, cuando Manlio comprende que, para acceder a los consulados y dictaduras, requiere del apoyo de la plebe, puesto que entre los patricios no lo logra, primero se acerca a los tribunos de la plebe con quienes comparte sus planes; luego decide pagar las deudas de los plebeyos para ganarse su apoyo, ${ }^{32}$ y por último planea la venta de su propiedad de Veyes para seguir teniendo recursos. ${ }^{33}$

Siguiendo su plan, Manlio se dirige al foro y ahí paga la deuda de un famoso centurión, un compañero de armas. Puesto que la intención de Manlio es difundir lo que hará a partir de ese momento, expresa en voz alta sus razones de pagar la deuda del centurión. En este breve discurso, reitera su proeza en el Capitolio para manifestar la coherencia de sus actos: entonces salvó a sus compañeros de ser capturados por los galos, ahora también los salva de ser llevados a la esclavitud. ${ }^{34}$ La diferencia

${ }^{30}$ Hinojo señala que impotens a veces está acompañado de adjetivos como vehemens, pp. 203-204.

${ }^{31}$ Liv., VI, 6, 3-7.

${ }^{32}$ Liv., VI, 11, 6-9.

${ }^{33}$ Liv., VI, 14, 9-10.

${ }^{34}$ Liv., VI, 14, 3-4. 
que Livio desea destacar entre uno y otro acto se sitúa en que antes Manlio había luchado por la libertad de Roma, en cambio, ahora se interesa por la libertad personal. ${ }^{35}$ En ello reside el peligro, antes Manlio vio por el bien de la ciudad y, por eso, fue reconocido; ahora, en cambio, está actuando a favor de un grupo.

El resultado inmediato de este acto es la adhesión incondicional del centurión. A través de un discurso puesto en boca de éste, queda claro que Manlio ha logrado su objetivo: el centurión le manifiesta su agradecimiento y lo llama "su libertador" y "padre de la plebe" ${ }^{36}$ La advertencia del autor sobre el peligro que conllevan estas palabras y acciones la manifiesta en una sola frase: "la plebe, instigada con estas palabras, era ya de un solo hombre" (his uocibus instincta plebes cum iam unius hominis esset). ${ }^{37}$ Esta escena constituye la primera prueba "de los efectos revolucionarios de la acción demagógica de Manlio".38

Al percatarse de la reacción de la plebe, Manlio da el siguiente paso: vende su propiedad de Veyes para poder pagar más deudas. La narración de esta parte del plan (desarrollada en pocas palabras) es la segunda prueba con la que el autor demuestra el peligro que encierran sus acciones. Al respecto, Livio hace dos comentarios: que la propiedad vendida era la parte principal del patrimonio de Manlio y que lo había hecho "para perturbar todo" (addita alia commodioris ad omnia turbanda consilii res). ${ }^{39}$ De esta manera, conduce al lector a interpretar a su modo la actuación de Manlio. Su desequilibrio es tal que no le importa atentar contra su patrimonio ni contra la res publica.

Las muestras de apoyo de la plebe ya son muy evidentes, así que Manlio intenta ahora enemistar a los plebeyos con los patricios. En las reuniones realizadas en su casa que se encuentra en el Capitolio, acusa a los patricios de haberse adueñado del oro destinado a pagar el rescate de la ciudad, recuperado por Camilo, y comenta que con ese oro podrían pagarse las deudas. ${ }^{40}$ Una vez más, Livio interviene para notar la indignación de quienes escuchan y el interés que despierta por saber dónde

\footnotetext{
${ }^{35}$ Gagé 1977, p. 355; Jaeger 1993, p. 355.

${ }^{36}$ Liv., VI, 14, 3-8.

${ }^{37}$ Liv., VI, 14, 9.

38 Valvo 1983, p. 28.

${ }^{39}$ Liv., VI, 14, 9-10.

${ }^{40}$ Liv., VI, 14, 11.
} 
se encuentra el oro; asimismo advierte que "no sería ambiguo el reconocimiento de una denuncia verdadera ni la ofensa de una falsa" (nec ueri indicii gratiam mediam nec falsi offensionem fore $).{ }^{41}$

Hasta aquí, la cantidad de sus seguidores, sus palabras, su liberalidad y su mentira no constituyen por sí mismos ninguna prueba de algún delito; por ello Livio necesita un motivo que agrave su desequilibrio y lo lleve a un comportamiento verdaderamente punible. Con esta intención, aparece la escena siguiente en la que Manlio es encarcelado. ${ }^{42}$ Lejos de obedecer al dictador en cuanto a delatar a quienes se han adueñado del oro, quizá por falta de pruebas,$^{43} \mathrm{o}$ a aceptar que su acusación es falsa, Manlio argumenta en favor de liberar a los deudores de los intereses que deben pagar por los préstamos, así como sobre la coherencia de sus actos: antes, durante el asedio de los galos, ayudó a todos en el Capitolio, ahora también ayudará a cada uno. ${ }^{44}$

A fin de sacar a Manlio de la cárcel, sus partidarios recurren a la protesta. Desde el momento de su detención, tanto la plebe como sus tribunos no se atrevieron a oponerse al dictador y se limitaron a manifestar su apoyo en la entrada de la cárcel. Pero cuando el dictador renuncia, se presenta la ocasión para actuar en favor de Manlio. En este caso, el autor presenta un nuevo discurso pronunciado ante la multitud reunida fuera de la cárcel. Su objetivo es hacer sucumbir la orden dictatorial y lograr la liberación de Manlio a través de una protesta más enérgica. Estos oradores (no identificados) les reprochan a los ahí reunidos su pasividad, para lo cual les recuerdan las historias bien conocidas de Casio, Melio y el propio Manlio: "así fue aniquilado Espurio Casio que llamó a la plebe a los campos; así, Espurio Melio que a expensas suyas quitó el hambre de la boca de los ciudadanos; así había sido entregado a sus enemigos Marco Manlio que sacó hacia la libertad y la luz a una parte de la ciudad, que estaba sumida y ahogada en la usura". ${ }^{45}$ Con esta breve evocación, los oradores logran advertir a los plebeyos que Manlio correrá la misma suerte que sus antecesores si no actúan. Al mismo tiempo, Livio deja en

${ }^{41}$ Liv., VI, 14, 11-13.

${ }^{42}$ Liv., VI, 15-16, 1.

${ }^{43}$ Gagé 1977, p. 353.

${ }^{44}$ Liv., VI, 15, 9-13.

${ }^{45}$ Liv., VI, 17, 1-2: sic Sp. Cassium in agros plebem uocantem, sic Sp. Maelium ab ore ciuium famem suis impensis propulsantem oppressos, sic M. Manlium mersam et obrutam fenore partem ciuitatis in libertatem ac lucem extrahentem proditum inimicis. 
la mente de su destinatario la idea de que se trata de historias similares; en consecuencia, Manlio aspira a ser rey de Roma igual que Casio y Melio. El discurso resulta convincente, pues los oradores consiguen que, por la presión de los plebeyos, el senado libere a Manlio.

Livio hace coincidir, en la narración de los hechos, el inicio de la gestión de los nuevos magistrados y las acciones que Manlio retoma una vez liberado. Como preparación para entender el desenlace, el autor describe el episodio maníaco del que Manlio es presa. El haber sido encarcelado le provoca enojo, pero al mismo tiempo se siente optimista porque el dictador no actuó contra él como Cincinato Quincio contra Espurio Melio, sino que renunció, y el senado tampoco pudo mantenerlo en la cárcel gracias al apoyo de sus seguidores. ${ }^{46} \mathrm{El}$ autor insiste, en pocas líneas, en los sentimientos que Manlio experimenta y en su incapacidad de controlarse: "más lleno de arrojo e ira que antes" (plenior aliquanto animorum irarumque quam antea fuerat), "la reciente ignominia encendía la ira en el ánimo inexperto ante la afrenta" (iram accenderat ignominia recens in animo ad contumeliam inexperto), "engreído y exacerbado" (inflatus exacerbatusque). ${ }^{47} \mathrm{El}$ arrojo e ira que siente lo llevan a arriesgarse, a considerar que ha llegado "la hora de intentar cosas mayores" (tempus est etiam maiora conari). ${ }^{48}$

Para presentar a Manlio como un auténtico aspirante al reino de Roma, Livio recurre a un discurso más, pronunciado en su casa ante los plebeyos más importantes con quienes hace planes para cambiar la situación política. ${ }^{49}$ Toda la argumentación está enfocada en persuadir a los plebeyos a la acción en caso de que sus enemigos quieran atacarlo, a que no lo dejen sólo y a que lo acompañen en el momento de impedir los juicios por deudas. ${ }^{50}$

Con este discurso, la preocupación del senado está ahora plenamente justificada, no sólo porque Manlio hace este llamado a la plebe sino por las ideas expresadas con el fin de hacer cambios profundos: "de arrasar con las dictaduras y los consulados para que la plebe romana pueda levantar la cabeza" (solo aequandae sunt dictaturae consulatusque, ut caput attolere

\footnotetext{
${ }^{46}$ Liv., VI, 18, 4.

${ }^{47}$ Liv., VI, 18, 3-5.

${ }^{48}$ Liv., VI, 18, 13.

${ }^{49}$ Liv., VI, 18, 3 .

${ }^{50}$ Liv., VI, 18, 5-9 y 14.
} 
Romana plebes possit). ${ }^{51}$ Además, su insistencia en recordar su hazaña en el Capitolio es un recordatorio a los romanos de que "who saved the 'head' of Rome should be the head of Rome". ${ }^{52}$ Por si esto fuera poco, en la parte final del discurso, Manlio deja escapar una frase que lo delata: "si llamáis a vuestro jefe con un nombre tanto más insigne por su mando o por su honor, cuanto más gozaréis de poder para obtener las cosas que vosotros queráis". ${ }^{33}$ No hace falta que Livio haga algún comentario.

Con este discurso, Manlio deja al descubierto que sus motivos para acercarse a la plebe son totalmente personales; su ambición de poder lo ha impulsado a actuar a favor de la plebe. Por tanto, el senado y los magistrados deben deliberar qué hacer ante esta amenaza a la libertad..$^{54} \mathrm{La}$ preocupación del senado es mayor por el hecho de que la casa de Manlio se encuentra en el Capitolio.

La reunión del senado se lleva a cabo en una casa situada también en el Capitolio. La única solución es acabar con Manlio, de manera que la discusión se centra en la forma de hacerlo. La primera opinión es actuar como Servilio Ahala, que apuñaló a Espurio Melio; no obstante, prevalece finalmente una opinión, como señala el autor, más suave en las palabras pero con la misma fuerza: "que los magistrados vean que la República no reciba ningún daño por los planes perniciosos de Manlio". ${ }^{55}$ Ésta es la fórmula del decreto senatorial conocido como senatus consultum ultimum. Medida excepcional a la que se recurría a fin de restablecer el orden y salvaguardar la seguridad de la res publica cuando se consideraba que alguna situación interna podría alterar gravemente el orden constitucional vigente. Con esta medida se encargaba a los cónsules la defensa de la res publica. Desde la perspectiva de la clase gobernante, y sobre todo del sector más conservador de la aristocracia, todo ciudadano que pretendiera cambios constitucionales se volvía sospechoso y era declarado enemigo del estado romano (hostis publicus).

En este caso, Livio no se atreve a llegar tan lejos: en ningún momento llama hostis a Manlio, ni ningún tribuno se anima a actuar de manera

${ }^{51}$ Liv., VI, 18, 14.

52 Jaeger 1993, p. 354.

${ }^{53}$ Liv., VI, 18, 15: uos si quo insigni magis imperii honorisue nomine uestrum appellabitis ducem, eo utemini potentiore ad obtinenda ea quae uoltis.

${ }^{54}$ Liv., VI, 19.

55 Liv., VI, 19, 3: ut uideant magistratus ne quid ex perniciosis consiliis M. Manli res publica detrimenti capiat. 
violenta y arbitraria. Fue necesaria la deliberación para encontrar una forma legal de ejecutarlo sin dar lugar a la plebe para una intervención a favor de Manlio. Por ello es que los tribunos de la plebe proponen reinterpretar las acciones de Manlio para que la plebe lo vea como una amenaza a su libertad: "mirarán a un reo patricio y en medio el delito de pretender el reino; a nadie favorecerán más que a su propia libertad". ${ }^{56}$

La estrategia consiste en usar el tópico de la aversión que los romanos sintieron, desde que los reyes fueron expulsados de Roma, contra la persona que pretendiera obtener un poder absoluto y despótico (regnum), incompatible con la res publica. ${ }^{57}$ De esta manera, el autor explica la razón por la que ningún familiar o amigo acompaña a Manlio en el juicio, pues estaban convencidos del peligro que representaba para la libertad. De igual modo se explica la actitud de la plebe. Livio señala que "la tardanza de condenarlo, para la plebe, no estuvo en la causa sino en el lugar". ${ }^{5}$

Según Livio, el problema al que se enfrentaron los tribunos fue el lugar donde se realizó la votación para condenar a Manlio. Desde el Campo Marte, se veía el Capitolio que recordaba su hazaña; así que hubo necesidad de cambiar el lugar de la votación al bosque Petelino, fuera de la puerta Flumentana, desde donde no se veía el Capitolio. Sólo entonces "la acusación prevaleció y, con ánimo resuelto, se realizó el juicio, triste y odioso incluso para los jueces". ${ }^{59}$ Es decir que lejos del Capitolio, del lugar que les recordaba la hazaña de ese gran hombre, fue posible que se dieran cuenta del peligro que representaba para la seguridad de la ciudad.

Con la recreación del episodio de Manlio basada en su deseo desmedido de honores y cargos públicos (impotens), Livio convalida la solución que los optimates tardorrepublicanos promovieron para justificar el asesinato de sus enemigos políticos. Según ellos, sus antepasados habían establecido la muerte como justo castigo para aquellos que atentaran contra la libertad, contra la res publica. Esos individuos se caracterizaron por adquirir gran popularidad gracias a sus medidas en favor de la plebe, pero con el fin verdadero de obtener el poder de la ciudad no lo-

${ }^{56}$ Liv., VI, 19, 7: patricium reum intuebuntur et regni crimen in medio, nulli magis quam libertati fauebunt suae. Jaeger 1993, p. 358.

${ }^{57}$ Liv., II, 8, 2

${ }^{58}$ Liv., VI, 20, 2-5.

${ }^{59}$ Liv., VI, 20, 11: ibi crimen ualuit et obstinatis animis triste iudicium inuisumque etiam iudicibus factum. 
grado por los medios institucionales. El episodio liviano es una muestra palmaria sobre la forma en que puede conformarse una imagen distinta de lo que en realidad era. Para una mayor eficacia, Livio sólo habla de los rasgos de la personalidad de Manlio que le permiten generar la transformación: en su propia forma de ser estaba el germen que lo llevaría a convertirse en un hombre peligroso para la ciudad.

\section{BIBLIOGRAFÍA}

\section{Ediciones}

Titi Livi, Ab Vrbe Condita, t. I (libri I-V) y t. II (libri VI-X), recognoverunt et adnotatione critica instruxerunt C. Flamstead Walters et R. Seymour Conway, Oxonii, E Typographeo Clarendoniano (Scriptorum Classicorum Bibliotheca Oxoniensis), 1970.

\section{Estudios especializados}

Álvarez SuÁREZ, U., Instituciones de derecho romano III, Madrid, Editorial Revista de Derecho Privado, 1977.

GaGÉ, J., "Les clients de M. Manlius Capitolinus et les formes de leur liberation", Latomus, 152, 1977, pp. 546-580.

Hellegouarch, J., "Le principat de Camille”, REL, 48, 1970, pp. 112-132.

Hinojo ANDRÉs, G., "El léxico político romano: speciosa uerba”, Voces, 8-9, $1997-$ 1998, pp. 191-206.

JAEGer, M. K., “Custodia Fidelis Memoriae: Livy's Story of M. Manlius Capitolinus", Latomus, 52, 1993, pp. 350-363.

LóPEZ GREGORIS, R., "La locura en Roma: un léxico como recurso literario y argumento político", Myrtia, 15, 2000, pp. 205-226.

LuQue Moreno, J., “Impotens: ¿impotente o prepotente (valde potens: Non., p. 187,6 L.)?", Revista de Estudios Latinos, 9, 2009, pp. 47-81.

Marco Simón, F. y F. PinA Polo, "Concordia y libertas como polos de referencia religiosa en la lucha política de la república", Gerión, 18, 2000, pp. 261-292.

MuÑzz Coello, J., "Entre la furia y la amentia. Dos casos de la antigua Roma", Gerión, 18, 2000, pp. 235-259.

PINA Polo, F., "El tirano debe morir: el tiranicidio preventivo en el pensamiento político romano", Actas y comunicaciones del Instituto de Historia Antigua y Medieval, 1/2, 2006, pp. 1-24.

RodríGuez EnNes, L., "Verdad y leyenda de la 'seditio manliana"”, Dereito, 13/2, 2004, pp. 91-110. 
Valvo, A., "La sedizione di Manlio Capitolino in Tito Livio", Memorie dell' Istituto Lombardo, XXXVIII/1, Milano, 1983.

Wiseman, T. P., "Topography and Rhetoric: The Trial of Manlius", Historia: Zeitschrift fûr Alte Geschichte, 28/1, 1979, pp. 32-50. 
